\title{
Differences in the Activity of Superoxide Dismutase, Polyphenol Oxidase and Cu-Zn Content in the Fruits of Gordal and Manzanilla Olive Varieties
}

\author{
Dámaso Hornero-Méndez, Lourdes Gallardo-Guerrero, Manuel Jarén-Galán \\ and María Isabel Mínguez-Mosquera* \\ Departamento de Biotecnología de Alimentos, Instituto de la Grasa, (CSIC), Av. Padre \\ García Tejero, 4. 41012 Sevilla, Spain. Fax: +34-954691262. E-mail: minguez@cica.es \\ *Author for correspondence and reprint request \\ Z. Naturforsch. 57c, 113-120 (2002); received September 18/October 19, 2001 \\ Superoxide Dismutase, Polyphenol Oxidase, Olive \\ Activity of the enzymes superoxide dismutase (SOD) and polyphenol oxidase (PPO) as \\ well as $\mathrm{Cu}-\mathrm{Zn}$ content have been monitored during the thirteen weeks growth of both Gordal \\ and Manzanilla olive variety fruits. These metalloenzymes, with $\mathrm{Cu}$ and $\mathrm{Zn}$ in the prostetic \\ group, are involved in controlling the redox balance in the chloroplast environment. The \\ results indicated that, under similar phenological and environmental conditions, there are \\ periodic peaks of SOD activity in both varieties, followed by fluctuations in the copper \\ content of the fruit. This was interpreted as a common and simultaneous response to situa- \\ tions of oxidative stress, and this response was more intense in the variety Gordal. The \\ enzyme PPO showed an activity peak at start of growth and then practically disappeared. \\ Thus, its activity cannot be correlated with situations of stress or with changes of $\mathrm{Cu}$ and $\mathrm{Zn}$ \\ in the fruit.
}

\section{Introduction}

Plants have their own enzymatic resources, such as the metalloenzymes superoxide dismutase (SOD) and polyphenol oxidase (PPO) to prevent oxidative damages, and both enzymes have been related with quality loss in foods of plant origin during the ripening and post-harvest of fruits and vegetables (Donnelly and Robinson, 1991). Cu-Zn SOD is the most abundant and the most widely distributed in the cell. Despite current knowledge on this enzyme, it is still in doubt whether its real catalytic activity is the same as that described in vitro. The sequence of reactions in which it takes part would mean in vivo eliminating a weak oxidizer and forming a strong one, requiring the involvement of a second enzyme, a catalase, for the neutralization. In principle, this mechanism seems somewhat complex and not very effective for neutralizing an agent that would affect only strong reducers (Donnelly and Robinson, 1991; Donnelly et al. 1989).

PPO is also a plastid copper-enzyme (Vaughn and Duke, 1984a) and its physiological activity is quite controversial. Its involvement in the plant's defense mechanisms against processes leading to traumatism is well known. However, neither its in- tracellular location nor its sequence of activity peaks is congruent with a single and specific activity of protection against external damage. Some studies relate this enzyme with reactions associated to photosynthesis and respiration (Vaughn and Duke, 1984b) and with the synthesis of phenolic compounds (Robb, 1984). All the activities demonstrated for or hypothesized for the enzyme PPO have the common requirement of oxygen as a substrate. The active and latent forms of the enzyme have in common that they are copperproteins, precipitable by interaction with the reaction products, and that in both, the ligand bond is relatively weak and easily removed by halogens and organic acids (Zawistowski et al., 1991).

Apparently SOD and PPO are related with the redox balance of the fruit and the protection of the chloroplast pigments against oxidative species. During fruit growth the amount and activity of these enzymes depend on the stress level. Later, during processing of fruits, cell integrity will be lost, which may structurally affect the copper-enzymes (SOD, PPO, and others such as cytochrome c oxidase), releasing the metal. High levels of SOD and PPO mean high oxidative potential in the environment of the chloroplast pigments and high levels of $\mathrm{Cu}$ available for exchange with the 
$\mathrm{Mg}$ ion of chlorophylls (or the proton of pheophytins) (Mínguez-Mosquera et al., 1995). A different behavior in SOD and PPO in the Gordal variety with respect to other varieties under similar growing conditions could be related with the appearance of the green staining alteration. The present study monitored weekly, during the thirteen weeks of fruit growth, the activity of the enzymes SOD and PPO and the $\mathrm{Cu}$ and $\mathrm{Zn}$ content in two olive varieties, Gordal, prone to develop the alteration, and Manzanilla, resistant to the alteration, were both subjected to identical growing conditions. Differences in the enzyme activity patterns or $\mathrm{Cu}$ $\mathrm{Zn}$ content between the variety of fruits used, both under the same environmental conditions, would indicate whether the alteration shows any varietydependent differences.

\section{Materials and Methods}

\section{Sampling and raw material}

Fruits of the varieties Gordal and Manzanilla were used. Fruits were picked from two single variety plantations devoted to the production of olives for industrial processing as table olives by the company Agroaceitunera S. A. (Utrera, Seville, Spain). In each plantation, 20 trees were selected, situated at various points and not subjected to any agronomic treatment during the whole study.

At each sampling and for each variety, 4 to $5 \mathrm{~kg}$ of fruits from the selected trees were harvested. The fruits were picked at random, sampling the whole perimeter of the tree at different heights and depths of the branches. Between 22 June and 28 September, 13 samplings were carried out at intervals of 7 days. The fruits were always picked between 9 and 11 in the morning. The evolution of the environmental temperature in the plantation zone along the harvest time was supplied by the Centro Meteorológico Territorial de Andalucia (Instituto Nacional de Meteorología, Spain).

All the fruits picked at each sampling were classified by the size of their equatorial circumference. For each uniform-sized group, the relative abundance, and the mean weight of the fruits included in the group, were established. The most-abundant sizes separated were selected for the study. The fruits selected as representative of each sampling were combined, and the mean weight, mean size, moisture, and stone weight were determined. Of the representative-sized fruits of the sampling, approximately $500 \mathrm{~g}$ were destoned and sliced, constituting the raw material for the analysis.

\section{Extraction and measurement of SOD activity}

The method of Almansa et al. (1989) was used for the enzyme extraction: $10.00 \mathrm{~g}$ of triturated fruit and $40 \mathrm{ml}$ of extracting buffer $50 \mathrm{~mm}$ Tris (tris[hydroxymethyl]aminomethane)- $\mathrm{HCl}$ at $\mathrm{pH} 7.5$, containing $0.1 \mathrm{~mm}$ EDTA, $5 \mathrm{~mm}$ cysteine, and Triton $\mathrm{X}-100(0.2 \% \mathrm{v} / \mathrm{v})$, were homogenized using an Ultra-Turrax model T-25 polytron homogenizer (Janke Kunkel, IKA-Laboratechnik, Germany), keeping the container in an ice bath. The homogenate was filtered through four layers of gauze and centrifuged in a refrigerated centrifuge BeckmanCoulter Avanty J-25 (Beckman Instruments España, S. A., Spain) at $8,000 \times g$ for $15 \mathrm{~min}$ at $10^{\circ} \mathrm{C}$; the supernatant was collected avoiding the oil droplets. The extract was dialyzed against a buffer of $50 \mathrm{~mm}$ Tris- $\mathrm{HCl}, \mathrm{pH} 7.5,0.1 \mathrm{~mm}$ EDTA, and $5 \mathrm{~mm}$ cysteine for $24 \mathrm{~h}$ with three changes of liquid and stirring in a cool room at $10{ }^{\circ} \mathrm{C}$. The dialyzed extract was divided into two aliquots: one to measure activity and the other for denaturation. The extract was denaturized in a thermostated bath at $100{ }^{\circ} \mathrm{C}$ for 20 minutes.

The method of Walker et al. (1987) was used for measurement of SOD activity: an aliquot of $0.1 \mathrm{ml}$ of enzyme extract was placed in a transparent glass test-tube and $4.9 \mathrm{ml}$ of $50 \mathrm{~mm}$ phosphate buffer, $\mathrm{pH} 7.8,2.34 \mu \mathrm{M}$ riboflavin, $4.3 \mathrm{~mm}$ TEMED ( $\mathrm{N}, \mathrm{N}, \mathrm{N}^{\prime}, \mathrm{N}^{\prime}$, tetramethylethylenediamine), $0.112 \mathrm{~mm}$ NBT (nitro blue tetrazolium) and $0.1 \mathrm{~mm}$ EDTA were added. As enzyme blank, $0.1 \mathrm{ml}$ of the denatured extract was placed in a completely opaque test-tube, and $4.9 \mathrm{ml}$ of reaction buffer were added. Another two test-tubes one transparent and the other opaque - containing $0.1 \mathrm{ml}$ of extraction buffer and $4.9 \mathrm{ml}$ of reaction buffer, were used as reaction blank. The reactions began on exposing the samples to light, and were left to run for exactly $6 \mathrm{~min}$. All the operations were carried out in a thermostated chamber at $10^{\circ} \mathrm{C}$ and in semidarkness and during the reaction time, the light intensity used to provoke the formation of superoxide radical was always the same. After the reaction time, in each sample, the 
absorbance at $560 \mathrm{~nm}$ was measured in a Hewlett Packard diode-array spectrophotometer 8452A. For each variety and each sampling, the enzyme extracts were made in quadruplicate and the activity was measured once in each extract.

In the reaction blank in darkness, the absorbance should be zero. In the reaction blank in the light, TEMED together with riboflavin in the presence of light generates superoxide radical that in the presence of NBT provokes the formation of formazan, which absorbs at $560 \mathrm{~nm}$. With the active extract in light, with identical compounds as before but with the presence of enzyme extract, SOD removes from the medium the superoxide radical formed, and the absorbance at $560 \mathrm{~nm}$ decreases with respect to the reaction blank in light. In the denaturized extract in darkness are computed all the possible side reactions that the enzyme extract could provoke in absence of light and which lead to an increase in absorbance at $560 \mathrm{~nm}$.

The activity unit (AU) is defined as the weight of fruit able to inhibit by $50 \%$ the increase in absorbance produced in the blank reaction. The results were expressed as units of enzyme activity per gram of dry weight of fruit and per destoned fruit.

\section{Extraction and measurement of PPO activity}

The method described by Sciancalepore and Longone (1984) for olives was used. A protein precipitate (acetone powder) of the fruit was prepared from $50 \mathrm{~g}$ of triturated destoned fruit extracted once with $100 \mathrm{ml}$ of acetone containing $2.5 \mathrm{~g}$ of polyethylene glycol at $-30{ }^{\circ} \mathrm{C}$. The residue was re-extracted 3 times with $100 \mathrm{ml}$ of acetone at $-30{ }^{\circ} \mathrm{C}$. This residue was dried and weighed. Acetone powder $(0.5 \mathrm{~g})$ was suspended in $25 \mathrm{ml}$ of $50 \mathrm{~mm}$ phosphate buffer at $\mathrm{pH} 6.2$, containing $1 \mathrm{M}$ $\mathrm{KCl}$. The suspension was stirred at $4{ }^{\circ} \mathrm{C}$ for $30 \mathrm{~min}$, and then centrifuged at $20,000 \times g$ for $20 \mathrm{~min}$ at $4{ }^{\circ} \mathrm{C}$. The supernatant was the enzyme extract and was divided into two aliquots: one for measurement of activity and the other for denaturation. The extract was denatured in thermostated bath at $100{ }^{\circ} \mathrm{C}$ for $20 \mathrm{~min}$.

The enzymatic reaction was performed in a spectrophotometric cuvette at room temperature. The reaction mixture comprised $0.5 \mathrm{ml}$ of enzyme extract and $2.5 \mathrm{ml}$ of substrate formed by $0.1 \mathrm{M}$ citrate buffer at pH 5.0, containing $8 \mathrm{~mm}$ 4-methylcatechol (Sciancalepore and Longone, 1984). The increase in absorbance at $410 \mathrm{~nm}$ was measured from 20 to 55 seconds and the reaction blank was taken measuring the increase in absorbance provoked by the denatured enzyme extract. For each variety and each sampling, the enzyme extracts were made in quadruplicate and the activity was measured once in each extract.

The activity unit (AU) is defined as the amount of fruit necessary to cause a change in absorbance of 0.05 absorbance units per min at $410 \mathrm{~nm}$. The results were expressed as units of activity per gram of dry weight of fruit and per destoned fruit.

\section{Determination of copper and zinc}

The fruits were washed, dried, destoned and triturated. Fifty grams of the triturated were homogenized with deionized water in a ratio of 1:1 to give a homogeneous paste. Twenty grams of this, weighed exactly, were dried in a porcelain crucible and $2 \mathrm{ml}$ of $5 \%(\mathrm{w} / \mathrm{v}) \mathrm{Mg}\left(\mathrm{NO}_{3}\right)_{2}$ solution in ethanol added. The resulting mixture was heated at $450{ }^{\circ} \mathrm{C}$ for $8 \mathrm{~h}$, and the resulting ash was bleached (if necessary) with $2 \mathrm{ml}$ of concentrated $\mathrm{HNO}_{3}$. The ash obtained was dissolved with two portions of $2 \mathrm{ml}$ of hot $6 \mathrm{~N} \mathrm{HCl}$, made up to $25 \mathrm{ml}$ with deionized water and vacuum-filtered through paper S \& S Rundfilter 589 Schwarzband.

Copper and zinc were determined by atomic absorption spectrophotometry (AAS QBC 932AA), atomizing the sample in an air/acetylene flame and using a hollow cathode lamp of copper and zinc. Absorbance was measured at $324.7 \mathrm{~nm}$ for copper and $213.9 \mathrm{~nm}$ for zinc with a slit of $0.5 \mathrm{~nm}$ in both cases.

\section{Reagents}

For all purposes, analytical grade reagents were used (Panreac, Barcelona, Spain). The deionized water used was obtained from a Milli- $Q^{\circledR} 50$ system (Millipore Corporation, Milford, MA).

\section{Results and Discussion}

Fruit growth

Figure 1 showed the relationship between average fruit weight and size along the growth 

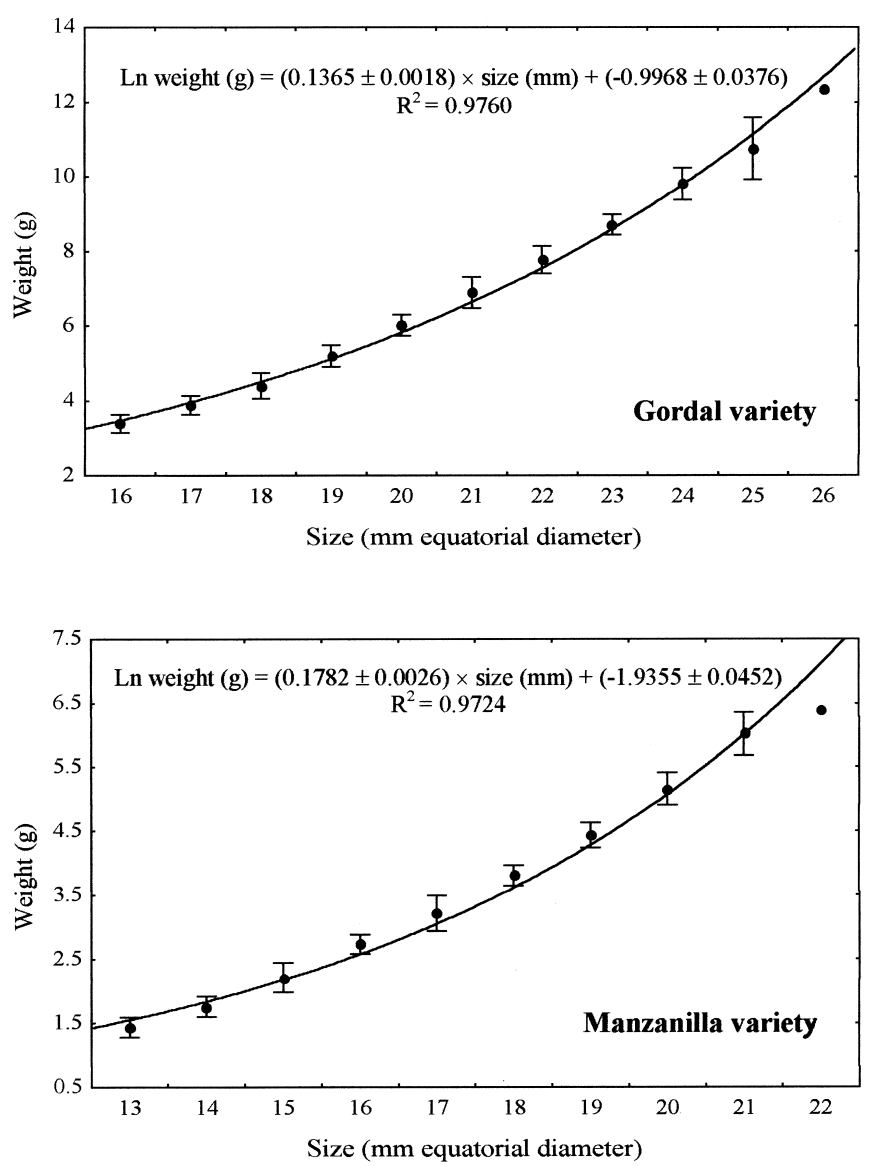

Fig. 1. Variation of size and weight during the olive fruit growth in the Gordal and Manzanilla varieties. period of Manzanilla and Gordal variety fruits. Both variables (fruit weight and size) were correlated $\left(\mathrm{R}^{2}>0.97\right)$ according to the resulting equations (see Figure), and therefore they could be used interchangeably. Fruit growth was under same temperature conditions (average $\mathrm{T}_{\text {max }}: 35^{\circ} \mathrm{C}$ and average $\mathrm{T}_{\min }: 20^{\circ} \mathrm{C}$ ).

\section{Changes in SOD activity}

Enzyme activity is given in Figure 2. When expressed as gram of fruit (Fig. 2A), during the first four weeks of growth, in both Manzanilla and Gordal, there was a trend of maintenance of activity values into a relatively narrow band. In the Gordal variety, this trend continued until week V, whereas at that time in the Manzanilla variety there was a sharp fall in SOD activity. Beyond week $\mathrm{V}$, there was a marked increase in activity of this enzyme in both varieties, which gradually fell, and around week IX reached levels similar to those of before the peak of activity. In week X, there was a new surge of activity, with levels in both varieties quantitatively similar to those of the first peak detected. Activity then fell gradually, until a further peak in week XIII.

Except in the determination for week $\mathrm{V}$, the profiles of activity were parallel in the two varieties. The only noteworthy feature was that in the series of appearing peaks after week V, the fluctuations between maximum and minimum were more marked in Gordal. In the two varieties, the series of maxima and minima was identical in time. Quantitatively, the two varieties had a similar level of activity in all the samplings, with a slight tendency to higher values in Gordal.

When the enzyme activity was expressed per fruit (Fig. 2B), the changes were qualitatively sim- 
Superoxide dismutase
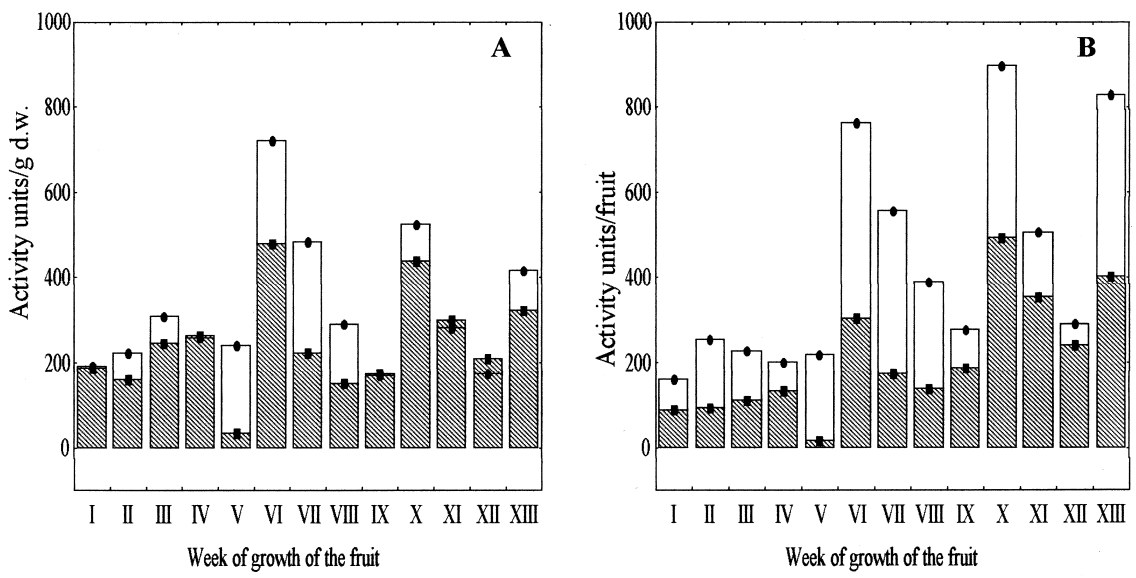

Polyphenol oxidase
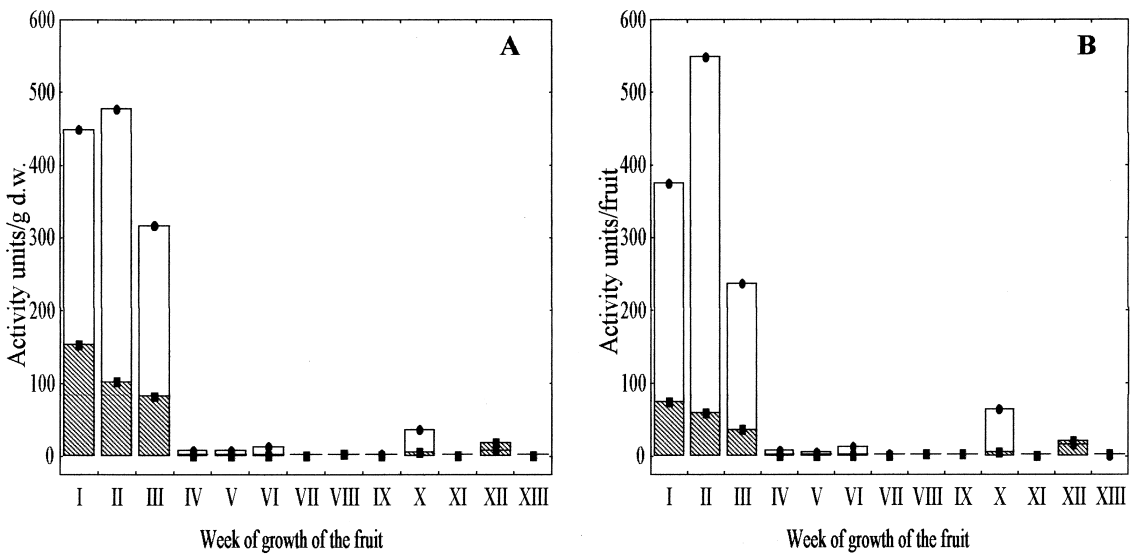

Fig. 2. Changes in enzyme activity during the growth of olive fruits of the Gordal ( $\square$ ) and Manzanilla ( $\square$ ) varieties. Data represent mean of four determinations (A: activity units per gram of fruit; B: activity units per fruit).

ilar. The main difference was in the quantitative levels. The fruit of the Gordal variety is heavier and much more fleshy than that of Manzanilla; consequently, the whole fruit of Gordal had greater activity. The graph showed that levels of activity reached in Gordal were much higher than those in Manzanilla.

Whether the results were expressed in the form of enzyme activity per gram of dry weight of fruit or per fruit, a series of maxima and minima appeared systematically from week V. Because the enzyme SOD is involved in controlling the superoxide radical, its increased activity was probably the response of the fruit to a specific physiological situation in which there was an increase in the production of this radical. The interval between peaks of activity, and probably between moments of maximum production of superoxide radical in the fruit, ranged between three and four weeks, and the peak was repeated up to three times. The last peak detected coincided with the end of growth, so that industrially, fruits picked in a period of two weeks around the last point of growth analyzed would include those of very high activity (and thus with a high production of superoxide radical) and those of low activity (with a low production of this radical). 
It is difficult to find a common cause explaining the appearance of synchronous pulses of activity in two different varieties, grown in two places some $10 \mathrm{~km}$ apart, and picked from trees not subjected to any type of treatment. The only causes that could be considered common to the two varieties were the climatic conditions - high temperature and lack of rain (heat and water stress) triggering simultaneously in both varieties protection mechanisms that were similar but of different intensity.

\section{Changes in PPO activity}

In contrast to the case of SOD, the results of PPO activity per gram of fruit in the Gordal and Manzanilla varieties showed marked differences both qualitatively and quantitatively (Fig. 2A). In Gordal, activity at the first sampling was very high, reaching the maximum in week II of growth. Activity then fell gradually and practically disappeared in week IV. From then on, the activity was extremely low (and in some cases, zero), until week $\mathrm{X}$, when a second peak of activity was detectable, although quantitatively very much lower than the peak found in week II. Then, activity fell again to zero, with a third, almost imperceptible, peak of activity in week XII. In the last sampling, week XIII, activity was zero.

In the Manzanilla variety, the peak of maximum activity was detected in the first sampling, and was quantitatively almost one third of the peak found in the Gordal variety. Activity then fell and, as in Gordal, became practically zero in week IV. It remained at this level until week X. In that sampling, coinciding with the situation in the Gordal variety, there was a second peak of activity that was, like the first one, quantitatively smaller in this variety. Subsequently, activity returned to zero, and in week XII, again as in the Gordal variety, there was a third peak of activity, although this time, the activity measured in Manzanilla was greater than in Gordal. In the following sampling, coinciding with the end of the study of growth, activity was practically zero.

When expressed as units of activity per fruit (Fig. 2B), the activity profiles were maintained, but the quantitative differences changed markedly. The peak of activity in the Gordal variety became almost 8 -fold that in the Manzanilla variety. This form of expressing the results modifies the baseline of PPO activity somewhat only in the Manzanilla variety. Some determinations of around zero in the expression of results per gram of dry weight of fruit, when multiplied by the fruit weight, reached values a little more appreciable.

The activity of PPO during fruit growth in the Gordal and Manzanilla varieties did not seem to be that of an enzyme involved in fruit protection against traumatisms. The maximum activity was in the initial phases of growth. Later, except for some individual determinations, the levels of activity were close to zero. If the role of this enzyme is exclusively defensive, it would have to be assumed that in this fruit it was formed during very early stages and inactivated during growth, remaining as a latent enzyme, available to act against traumatisms.

Certain differences between varieties were found in the activity profile for SOD and PPO. When enzyme activity is expressed per gram of fruit, the Gordal variety showed extreme behavior. The peaks of SOD activity were higher, which could be interpreted as a greater susceptibility of this variety to oxidizing damage and consequently requiring a more drastic response. The peak of PPO activity was also much higher in Gordal, although the activity of this enzyme did not seem to be involved in the creation or protection of an oxidizing environment around the chloroplast, as the levels of activity in both varieties were practically zero from week III.

Relationship between changes in $\mathrm{Cu}$ and $\mathrm{Zn}$ content and SOD and PPO activities during fruit growth.

Figure 3 shows changes in $\mathrm{Cu}$ and $\mathrm{Zn}$ levels during fruit development and growth (13 weeks). It was observed that the content (expressed in $\mu \mathrm{g} / \mathrm{g}$ dwt) of both metals increased for both varieties, being this increase more denoted during the first 5 weeks, coinciding with higher growth rates. Between weeks VI and VIII, it reached maximum levels (around 15 and $13 \mu \mathrm{g} / \mathrm{g}$ dwt for Gordal and Manzanilla respectively), to fall slightly in later weeks. The levels of $\mathrm{Cu}$ were similar in the two varieties throughout the fruit growth period, whereas the levels of $\mathrm{Zn}$ were slightly higher in the Gordal variety. When the results were expressed as $\mu \mathrm{g}$ of metal per fruit (Fig. 3), the $\mathrm{Cu}$ and $\mathrm{Zn}$ contents were always markedly higher in the Gordal variety. 

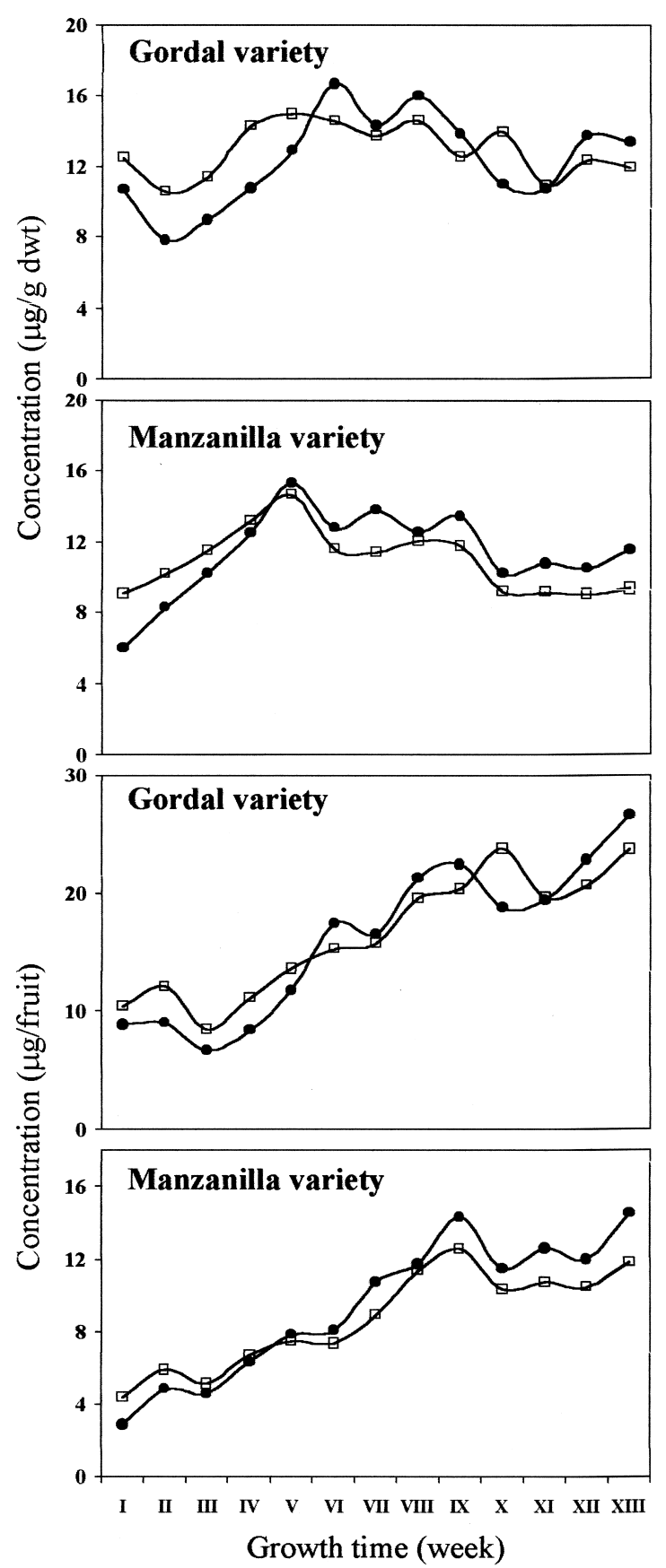

Fig. 3. Changes in copper $(\bullet)$ and zinc $(\square)$ content during the growth of olive fruits of the Gordal and Manzanilla varieties.
Although these were measurements of total $\mathrm{Cu}$ and $\mathrm{Zn}$ content in the fruits, comparison of the profile of changes in these micronutrients with that of changes in the activity of SOD (Fig. 2A and 2B) - an enzyme that contains $\mathrm{Cu}$ and $\mathrm{Zn}$ in its prosthetic group - shows a certain correlation between the small sawtooth-like variations in the changes of metals and the well-defined series of maxima and minima shown by the curve of SOD activity. This relationship was greater in the Gordal variety, and somewhat delayed (approx. 1 week) in the Manzanilla variety. An explanation might be that the higher SOD levels at certain moments were related with a temporary defensive response to a greater oxidative stress due to extreme climate conditions, which are typical at this time of year. To prevent damages, the plant increase its defensive mechanism. The equivalence of the peaks of SOD activity in the two varieties supported the effect of environmental factors as cause of the appearance of the maxima and minima of activity. In such situation, the higher levels of SOD activity in the Gordal variety indicated that these fruits were more prone to oxidative stress and thus required a greater response of defense than did those of the Manzanilla variety. The greater correspondence between peak levels of $\mathrm{Cu} / \mathrm{Zn}$ and peak activity of the enzyme SOD suggested that the response to stress was more rapid in the Gordal variety. The delay observed in the Manzanilla variety would mean a slower response time, with the plant's $\mathrm{Cu} / \mathrm{Zn}$ assimilation demand being out of step with the peak of SOD activity.

\section{Acknowledgements}

We express our sincere gratitude to CICYT-EU (Spanish Government and European Union, FD 97-0925) for financial support of this research. We thank to Mrs. M. Bodineau-Bada for technical assistance. 
Almansa M. S., del Rio L. A., Alcaraz C. F. and Sevilla F. (1989), Isoenzyme pattern of superoxide dismutase in different varieties of citrus plants. Physiol. Plant. 76, $563-568$

Donnelly J. K. and Robinson D. S. (1991), Superoxide dismutase. In: Oxidative Enzymes in Foods (Robinson, D. S. and Eskin N. A. M., Eds.). Elsevier Applied Science, London and New York, pp. 49-91.

Donnelly J. K., McLellan K. M., Walker J. L. and Robinson D. S. (1989), Superoxide dismutase in foods. A review. Food Chem. 33, 243-270.

Mínguez-Mosquera M. I., Garrido-Fernández J., Gallardo-Guerrero L. and Hornero-Méndez D. (1995), Involvement of copper on the "green mark" alteration in Gordal variety table olives. J. Food Protec. 58, $564-569$.

Robb D. A. (1984), Tyrosinase. In: Copper Proteins and Copper Enzymes, Vol. II. (Lontie R., ed.). CRC Press, Boca Raton, Florida. pp. 207-241.
Sciancalepore V. and Longone V. (1984), Polyphenol oxidase activity and browning in green olives. J. Agric. Food Chem. 32, 320-321.

Vaughn K. C. and Duke S. O. (1984), Function of polyphenol oxidase in higher plants. Minireview. Physiol. Plant. 60a, 106-112.

Vaughn K. C. and Duke S. O. (1984), Tentoxin stops the processing of polyphenol oxidase into an active enzyme. Physiol. Plant. 60b, 257-262.

Walker J. L., McLellan K. M. and Robinson D. S. (1987), Heat stability of superoxide dismutase in cabbage. Food Chem. 23, 245-256.

Zawistowski J., Biliaderis C. G. and Eskin N. A. M. (1991), Polyphenol oxidases. In: Oxidative Enzymes in Foods. (Robinson D. S., Eskin N. A. M., eds.). Elsevier Applied Science, London, New York. pp. 217-273. 